\title{
A Pandemia da Covid-19: Repercussões do Ensino Remoto na Formação Médica
}

\author{
The Covid-19 Pandemic: Repercussions of Remote Education on \\ Medical Training
}

\author{
Vânia Thais Silva Gomes ${ }^{I}$ (i) \\ Roberto Oliveira Rodrigues ${ }^{I I}$ (ID \\ Raimundo Nonato Silva Gomes ${ }^{I I I}$ (D) \\ Maria Silva Gomes ${ }^{I V}(\mathbb{D}$ \\ Larissa Vanessa Machado Viana ${ }^{V}$ (D) \\ Felipe Santana e Silva ${ }^{I I}$ (1)
}

Cara Editora,

Em dezembro de 2019, foi descoberto um novo vírus, denominado SARS-CoV-2, que causa a doença COVID-19, assim denominada pela Organização Mundial da Saúde (OMS). O SARS-CoV-2 surgiu inicialmente na cidade de Wuhan, na China, e se espalhou rapidamente por todo o mundo. Já em 30 de janeiro de 2020, a OMS reconheceu o surto dessa nova doença como uma emergência de saúde pública de importância internacional, que é considerado o maior nível de alerta. Posteriormente, no dia 11 de março de 2020, a OMS caracterizou a COVID-19 como uma pandemia ${ }^{1}$.

Até o dia 08 de julho de 2020, no mundo, foram registrados 11.994 .182 casos da COVID-19 e 547.931 óbitos. No Brasil, nessa mesma data, já haviam sido confirmados 1.716 .196 casos da doença e 68.055 óbitos. O vírus é transmitido através de gotículas respiratórias, do contato direto ou objetos e de superfícies contaminadas. Ou seja, a doença possui múltiplas vias de transmissão, fato que justifica a grande necessidade de distanciamento social ${ }^{1}$.

Com o distanciamento social, medida profilática mais efetiva contra a doença, houve a necessidade de reavaliação do processo de ensino-aprendizagem, visto que o distanciamento social obrigou estudantes de medicina do mundo inteiro a adotar tecnologias da informação e comunicação (TIC) para continuar com a rotina de estudos. Assim, as TICs e a internet têm sido cada vez mais utilizadas pelas instituições de ensino superior para suprir essa ausência nas salas de aulas. No entanto, devemos questionar se esse novo método de ensinar e aprender, denominado homeschooling, pode influenciar na formação de estudantes de medicina.

Com o advento da pandemia, as estratégias de ensino remoto são importantes meios de contenção dos efeitos do distanciamento social; no entanto, as evidências sugerem que inúmeras lacunas serão criadas sem a interação professor-estudante de medicina. Nesse sentido, para o pós-pandemia, é indispensável que as instituições de ensino planejem um robusto conjunto de ações para garantir o contato do estudante de medicina com pacientes, sejam em hospitais, ambulatórios ou na atenção primária em saúde.

Além das estratégias de ensino utilizadas por instituições de educação, é necessária uma regulamentação do Ministério da Educação (MEC) e demais órgãos regulamentadores. Assim, em 28 de abril, o Conselho Nacional de Educação (CNE) aprovou por unanimidade a resolução com diretrizes para orientação sobre aulas remotas durante a pandemia.

A Portaria No 343, de 17 de março de 2020, dispõe sobre a substituição das aulas presenciais por aulas remotas enquanto durar a pandemia da COVID-19. A Portaria veta a substituição de aulas práticas e estágios no curso de medicina. Já em 16 de junho de 2020, o MEC publica a Portaria No 544, autorizando a substituição de estágio e práticas por aulas remotas no curso de medicina. Seguindo as recomendações do MEC, as faculdades de medicina do país podem interromper esse contato prático durante a pandemia, o que certamente poderá comprometer o processo de formação de estudantes de medicina, uma vez que o contato com doentes é essencial para sedimentar conhecimentos teóricos.

Recebido em 10/7/20

Aceito em 18/7/20

REVISTA BRASILEIRA DE EDUCAÇÃO MÉDICA

44 (4) : e114; 2020
${ }^{\mathrm{I}}$ Universidade de Gurupi, Gurupi, Tocantins, Brasil.

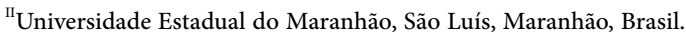

${ }^{\mathrm{III}}$ Universidade Federal do Rio de Janeiro, Rio de Janeiro, Rio de Janeiro, Brasil.

${ }^{\mathrm{IV}}$ Força Estadual de Saúde do Maranhão, São Luís, Maranhão, Brasil.

${ }^{\mathrm{v}}$ Universidade Federal do Acre, Rio Branco, Acre, Brasil. 
Além disso, no curso de medicina, as relações humanas são de extrema relevância na construção do conhecimento e no estabelecimento de uma boa inter-relação. A prática médica requer mais do que conhecimento técnico, necessita de habilidades que possibilitem um cuidado humanizado e integral. Essas habilidades são cada vez mais necessárias à sociedade, o que fundamenta a necessidade de contato humano como parte sine qua non na formação médica. A fragilidade psicossocial provocada pela pandemia da COVID-19 é um grande exemplo da necessidade de um médico humanizado e com ampla capacidade de interação com o paciente/familiar ${ }^{2}$.

Com a mudança do perfil de estudantes de medicina e das instituições de ensino, nunca foi tão necessário diversificar os métodos de ensino-aprendizagem. Assim, no contexto da pandemia da COVID-19, existe a necessidade de uma diversidade de suportes e métodos para apoiar a criação de uma rotina positiva para os estudantes de medicina. Para que os estudantes de medicina consigam superar as barreiras educacionais impostas pela pandemia, é necessário que haja resiliência e que as instituições de ensino garantam um cenário de aprendizagem com metodologias ativas e inovadoras; assim, poderemos herdar um legado no pós-pandemia que possa contribuir na formação de novos médicos.

Seguindo as Diretrizes Curriculares Nacionais (DCN) para o curso de graduação em Medicina, de 2014, o graduado em medicina deve ter uma formação generalista baseada no compromisso com o respeito e defesa à cidadania, à dignidade humana e à integralidade do ser humano. Além disso, terá como eixo transversal na sua prática médica diária os determinantes sociais do processo de saúde-doença. No entanto, o homeschooling pode não ser suficiente para atender às necessidades interacionais no processo de formação de um médico mais calcado nos princípios da Política Nacional de Humanização e nas DCN vigentes ${ }^{2,3}$.

A aquisição de habilidades de comunicação efetiva é um dos pilares da formação médica, sendo necessária para a interação com colegas de trabalho, usuários e familiares. A efetiva comunicação está na base da formação de médicos, não apenas para a realização da anamnese, mas também para a construção de uma relação de parceria médico-paciente. A educação a distância (ensino remoto) é um grande obstáculo à aquisição dessa habilidade, uma vez que as TICs dificultam a interação professorestudante e estudante-estudante, processo indispensável à construção de uma boa comunicação ${ }^{2,4}$.

A simples observação da interação do professor com o doente em estágios e práticas clínicas permite ao estudante de medicina organizar um raciocínio clínico e inferir possíveis condutas diagnósticas e terapêuticas. Além disso, o contato humano permite ao estudante a compreensão da realidade humana e social em que está inserido e como pode interferir na vida de um doente/familiar ${ }^{4,5}$.

Nessa perspectiva, a interação com o professor tem um papel extremamente relevante na construção do conhecimento do estudante de medicina. O papel de facilitador desempenhado pelo docente é mais efetivo quando existe o vínculo garantido pela interação professorestudante. Nesse sentido, o ensino-aprendizagem à "beira leito" tão necessário à formação médica ficou inviável durante a pandemia da
COVID-19. Assim, faz-se necessário um processo de construção de novas metodologias direcionadas à garantia de uma boa formação aos estudantes de medicina à luz da nova legislação e da pandemia da COVID-19.

Por fim, a necessidade de ressignificar o ensino de medicina é extremamente necessária e a pandemia da COVID-19 trouxe consigo as TICs como alternativa ao isolamento social; no entanto, é necessário ter em mente que a formação do médico vai muito além da aquisição de habilidades técnicas (possivelmente garantidas pela TICs); ela requer interação presencial professor-estudante, estudante-estudante e estudante-paciente.

\section{REFERÊNCIAS}

1. Díaz-Castrillón FJ, Toro-Montoya AI. SARS-CoV-2/COVID-19: el virus, la enfermedad y la pandemia. Med Laborat. 2020;24(3):183205. DOI: https://doi.org/10.36384/01232576.268

2. Moura ACA, Mariano LA, Gottems LBD, Bolognani CV, Fernandes SES, Bittencourt RJ. Teaching-learning strategies for humanistic, critical, reflective and ethical undergraduate medical training: a systematic review. Rev Bras Educ Med. 2020;44(3):67-76. DOI: https://doi.org/10.1590/1981-5271v44.3-20190189

3. Pimente CE, Vasconcelos MVL, Rodarte RS, Pedrosa CMS, Pimente FSC. Teaching and Learning in Supervised Internship: Integrated Internship in Health. Rev Bras Educ Med. 2015;39(3):352-358. DOI: http://dx.doi.org/10.1590/1981-52712015v39n3e01262014.

4. Meireles MAC, Fernandes CCP, Silva SL. Curricular guidelines and medical education: expectations of first year medical students at a higher education institution. Rev Bras Educ Med. 2019;43(2):67-78. DOI: http://dx.doi.org/10.1590/1981-52712015v43n2RB20180178

5. Gomez E, Azadi J, Magid D. Innovation Born in Isolation: Rapid Transformation of an In-Person Medical Student Radiology Elective to a Remote Learning Experience During the COVID-19 Pandemic. Acad Radiol. 2020;32(20):35-44. DOI:10.1016/j.acra.2020.06.001

\section{CONTRIBUIÇÃO DOS AUTORES}

Gomes VTS, Rodrigues RO, Gomes RNS, Gomes MS, Viana LVM e Silva FS participaram da concepção, delineamento, análise e interpretação dos dados, escrita do manuscrito e revisão crítica do conteúdo. Todos os autores aprovam a versão final a ser publicada.

\section{CONFLITO DE INTERESSES}

Não existe.

\section{ENDEREÇO PARA CORRESPONDÊNCIA}

Raimundo Nonato Silva Gomes. Av. Carlos Chagas Filho, 373, Cidade Universitária da Universidade Federal do Rio de Janeiro, Rio de Janeiro, RJ, Brasil. CEP: 21941-590.

E-mail: raigomes.ufrj@gmail.com 